\title{
A two-centre survey of caregiver perspectives on opioid use for children's acute pain management
}

\author{
Esther Jun $\mathrm{MD}^{1}$, Samina Ali MDCM${ }^{1,2, \odot}$, Maryna Yaskina $\mathrm{PhD}^{2}$, Kathryn Dong MD $\mathrm{MSc}^{3,4}$, \\ Manasi Rajagopal BSc MBT ${ }^{1}$, Amy L. Drendel DO MS ${ }^{5}$, Megan Fowler MD ${ }^{1}$, Naveen Poonai MD MSc ${ }^{6,7}$; \\ on behalf of Pediatric Emergency Research Canada*

\begin{abstract}
${ }^{1}$ Department of Pediatrics, Faculty of Medicine \& Dentistry, University of Alberta, Edmonton, Alberta; ${ }^{2}$ Women and Children's Health Research Institute, University of Alberta, Edmonton, Alberta; ${ }^{3}$ Department of Emergency Medicine, Alexandra Hospital, Edmonton, Alberta; ${ }^{5}$ Department of Pediatrics, Section of Emergency Medicine, Medical College of Wisconsin, Milwaukee, Wisconsin, USA; ${ }^{6}$ Children's Health Research Institute, London Health Sciences Centre, London,
\end{abstract} \\ Faculty of Medicine \& Dentistry, University of Alberta, Edmonton, Alberta; ${ }^{4}$ Inner City Health and Wellness Program, Royal \\ Ontario; ${ }^{7}$ Department of Pediatrics, Schulich School of Medicine and Dentistry, Western University, London, Ontario
}

Correspondence: Samina Ali, Department of Pediatrics, 3-583 Edmonton Clinic Health Academy, 11405 - 87 Avenue, Edmonton, Alberta T6G 1C9. Telephone (780)-248-5574, fax (888)-775-8876, e-mail sali@ualberta.ca

*A complete list of nonauthor contributors appears in Appendix 1.

\begin{abstract}
Background: Given the current opioid crisis, caregivers have mounting fears regarding the use of opioid medication in their children. We aimed to determine caregivers' a) willingness to accept, $b$ ) reasons for refusing, and c) past experiences with opioids.

Methods: A novel electronic survey of caregivers of children aged 4 to 16 years who had an acute musculoskeletal injury and presented to two Canadian paediatric emergency departments (ED) (March to November 2017). Primary outcome was caregiver willingness to accept opioids for moderate pain for their children.

Results: Five hundred and seventeen caregivers participated; mean age was 40.9 (SD 7.1) years with $70.0 \%(362 / 517)$ mothers. Children included 62.2\% (321/516) males with a mean age of 10.0 (SD $3.6)$ years. $49.6 \%$ of caregivers $(254 / 512)$ reported willingness to accept opioids for ongoing moderate pain in the ED, while $37.1 \%(190 / 512)$ were 'unsure'; $33.2 \%(170 / 512)$ of caregivers would accept opioids for at-home use, but $45.5 \%$ (233/512) were 'unsure'. Caregivers' primary concerns were side effects, overdose, addiction, and masking of diagnosis. Caregiver fear of addiction (odds ratio [OR] $1.12,95 \%$ confidence interval [CI] 1.01 to 1.25 ) and side effects (OR 1.25, 95\% CI 1.11 to 1.42 ) affected willingness to accept opioids in the emergency department; fears of addiction (OR 1.19, 95\% CI 1.07 to 1.32 ), and overdose (OR $1.15,95 \%$ CI 1.04 to 1.27 ) affected willingness to accept opioids for at-home use.

Conclusions: Only half of the caregivers would accept opioids for moderate pain, despite ongoing pain following nonopioid analgesics. Caregivers' fears of addiction, side effects, overdose, and masking diagnosis may have influenced their responses. These findings are a first step in understanding caregiver analgesic decision making.
\end{abstract}

Keywords: Caregiver; Emergency department; Musculoskeletal injury; Opioids; Pain 
While opioids are generally safe and effective short-term treatment for children with severe acute pain, caregivers (i.e., parents and legal guardians) are increasingly hesitant to administer them to their child, in the wake of the current opioid crisis $(1,2)$. Studies show that caregivers refuse opioids more frequently than nonopioid analgesics $(3,4)$, and will often not request a stronger pain medication even with ongoing pain (5-8).

Understanding caregivers' perceptions of opioids is essential for improving overall pain management for children $(5,9,10)$. Caregivers are the gatekeepers to their child's pain management and they have unique expertise regarding their child's temperament, behaviour, and pain response (11). By soliciting caregivers' views and experiences, we can incorporate this knowledge into clinical care to enhance effective communication and ultimately improve patient satisfaction (12-15).

Previous studies have explored caregiver attitudes toward analgesia in general (16-19). To our knowledge, no study has specifically examined caregiver perspectives and experiences with opioids in the context of acute injury. We aimed to determine caregivers': a) willingness to accept opioids for analgesia, b) fears and barriers regarding opioids, and c) past experiences with opioids. We further evaluated the association between caregiver perceptions and their willingness to use opioids in order to identify which caregiver perceptions and experiences might affect their decision making.

\section{PATIENTS AND METHODS}

\section{Study design and setting}

This study was a descriptive cross-sectional survey. We consecutively enrolled caregivers accompanying children with an acute musculoskeletal (MSK) injury presenting to the Stollery Children's Hospital (Edmonton, Alberta) and the Children's Hospital at London Health Sciences Centre (London, Ontario) emergency departments (EDs) between the hours of 3 and 11 pm, 7 days per week, from May to November 2017. Both sites are tertiary care paediatric EDs in large urban centres, with an annual census of 40,000 to 58,000 visits, respectively. Ethics approval was obtained from the Health Research Ethics Board (University of Alberta) and Health Science Research Ethics Board (Western University). This study was endorsed by Pediatric Emergency Research Canada.

\section{Survey design}

The design and administration of the survey adhered to previously published guidelines (20). An expert panel, including specialists in paediatric emergency, addiction, and pain medicine informed item generation, item reduction, and pretesting. Pilot testing and clinical sensibility testing were performed prior to finalizing the survey tool. Study variables included demographic characteristics, responses to hypothetical MSK injury vignettes, experiences, and attitudes toward opioids (Appendix 1).

\section{Participants and recruitment}

Caregivers were eligible for this study if they accompanied a child aged 4 to 16 years presenting to the ED with an MSK injury sustained within seven days of presentation. We excluded patients who were (a) deemed medically unstable by the treating team or (b) presented with altered level of consciousness; caregivers who lacked functional proficiency in English were also excluded. Research assistants (RA) identified potential participants, performed screening, and obtained verbal or written consent (per site requirements). Survey questions were anonymously answered via electronic tablet and responses were recorded through the secure, online Research Electronic Data Capture (REDCap) platform (21). Completion of the survey required approximately 10 minutes. Participants were offered a 5 gift card as a token of appreciation.

\section{Study outcomes and measurements}

The primary outcome was the proportion of caregivers willing to accept opioids for their child's on-going acute moderate pain in the ED and following discharge. Secondary outcomes were caregivers': a) fears and barriers to accepting opioids for their child's acute pain b) past experiences with opioids, and c) the relative risk of accepting opioids for their child based on the caregivers' perceptions and experiences.

\section{Statistical analysis}

Continuous data were summarized by the mean \pm standard deviation (SD) for approximately normally distributed variables or by median and first and third quartiles for skewed distributions. Categorical data were summarized using absolute and relative frequencies and percentages. Binomial logistic regression was performed to ascertain the association between caregiver's education, caregiver's personal history (e.g., substance use disorder), and concerns about opioid side effects, addiction, risk of overdose and masking of diagnosis, and a caregiver's willingness to accept opioids in a health care facility or at home use for moderate pain. These predictors were chosen, a priori, based on current literature and plausibility $(7,22,23)$. First, bivariate models were created to access individual effect and then variables with $P$-value $\leq 0.20$ were entered in a multivariate logistic regression. The regression analyses relating fears to willingness to accept opioids were based on moderate pain scenario responses, as moderate pain presents more variability in responses, as opposed to the severe pain situation, where acceptance rates are already quite high, and fears become less relevant in decision making. Unless stated otherwise, twosided $P$-values $<0.05$ were considered statistically significant. All statistical analyses were performed with SAS 9.4 (SAS Institute Inc., Cary, NC). 


\section{RESULTS}

\section{Demographic characteristics}

Five hundred and seventeen caregivers were surveyed (mean caregiver age of 40.9 years [SD 7.1 years]). The children included $62.2 \%(321 / 516)$ males with an overall mean age of 10.0 (SD 3.6) years (Table 1). The demographic characteristics of participants from both sites were notably similar.

\section{Caregiver willingness to accept opioids for analgesia}

When measured with an 11-point numerical rating scale (where $0=$ very unlikely to accept and $10=$ very likely to accept), caregivers' likelihood of accepting a nonpharmacologic treatment for their child was 8.5 (SD 2.8) for moderate and 7.9 (SD 3.6) for severe pain. They reported willingness to accept pain medication from a physician in the ED as 7.8 (SD 2.6) for moderate and 8.4 (SD 2.5) for severe pain. However, their rating dropped when asked if they would accept opioids in the waiting room from the nurse if nonopioid medication treatment was inadequate: 3.9 (SD 3.5) for moderate and 5.7 (SD 3.5) for severe pain. Figure 1 presents respondents' willingness to accept opioids for both moderate and severe pain scenarios. Figure 2 presents caregivers' top analgesic choices

Table 1. Child and caregiver demographics

\begin{tabular}{lc}
\hline Demographic characteristics & \\
\hline Child Age (years), Mean (SD) & $10.0(3.6)$ \\
Caregiver Age (years), Mean (SD) & $40.9(7.1)$ \\
Child Sex, n (\%) & $\mathrm{n}=516$ \\
$\quad$ Female & $193(37.4)$ \\
Injury Location, n (\%) & $\mathrm{n}=517$ \\
$\quad$ Face/Head & $40(7.7)$ \\
Neck/Back & $15(2.9)$ \\
Upper Limb & $288(55.7)$ \\
Lower Limb & $179(34.6)$ \\
Other* & $5(1.0)$ \\
Chronic Illness, $\mathrm{n}$ (\%) & $\mathrm{n}=509$ \\
$\quad$ Yes & $7(1.4)$ \\
Caregiver Relation to Child, $\mathrm{n}$ (\%) & $\mathrm{n}=517$ \\
Mother & $362(70.0)$ \\
Father & $125(24.2)$ \\
Other^ & $30(5.8)$ \\
Caregiver Education Level, $\mathrm{n}$ (\%) & $\mathrm{n}=514$ \\
Some Highschool/ trade & $223(43.4)$ \\
Some Bachelor’s/Incomplete University degree & $57(11.1)$ \\
Bachelor’s/Professional/Doctorate/Masters & $222(43.2)$ \\
\hline
\end{tabular}

*Other: ASIS avulsion fracture $(n=1)$, groin injury $(n=2)$.

^Other: Grandparent $(n=15)$, legal guardian $(n=6)$, aunt $(n-1)$, brother $(n=1)$, caregiver $(n=2)$, great grandmother $(n=1)$, stepmother $(\mathrm{n}=2)$, adoptive mom $(\mathrm{n}=1)$, kinship care provider $(\mathrm{n}=1)$. for moderate and severe pain scenarios. In both pain scenarios, ibuprofen was ranked the most appropriate pain medication, with acetaminophen as the second. Morphine ranked the third most appropriate analgesic for severe pain, however, 'unsure' was chosen as the third response for moderate pain. Combination medication therapies were included as an option for top analgesic choice if they were commercially available (i.e., acetaminophen-hydrocodone combination formulation); combining any of the listed monotherapy options was not permitted.

\section{Previous experience with pain medications}

Table 2 presents children's and caregivers' reported previous experience with pain medications. Notably, $12.6 \%$ of caregivers were unsure which analgesia their child had previously received in a health care facility.

$15.0 \%(76 / 506)$ of respondents stated that they, themselves, or a family member had been diagnosed with a substance use disorder or addiction, specifically to alcohol $(n=27)$, opioids $(\mathrm{n}=16)$, cocaine/'crack' $(\mathrm{n}=5)$, or methamphetamines $(\mathrm{n}=4)$. Further, $1.9 \%(10 / 509)$ of caregivers reported being prescribed methadone or buprenorphine for treatment of an opioid use disorder. 19.0\% (98/517) of caregivers reported personal recreational use of analgesics, of which 56.1\% (55/98) reported using opioids. 3.3\% (17/517) of caregivers believed their child had used analgesics recreationally—specifically, opioids (23.5\%, 4/17), non-steroidal anti-inflammatory drugs (29.4\%, $5 / 17)$, and acetaminophen $(23.5 \%, 4 / 17)$.

Caregivers were significantly more likely to refuse opioids for their child's persistent moderate pain in the ED (after appropriate doses of acetaminophen and ibuprofen) if they had never been personally prescribed opioids, compared to if they had been previously prescribed opioids (odds ratio [OR] 1.87, 95\% confidence interval $[\mathrm{CI}]: 1.02,3.42$ ). Caregiver education level and caregiver/family history of a substance use disorder did not influence willingness to accept opioids for their child in either the ED setting or for use at home (Supplementary Table 1).

\section{Caregiver perceptions regarding opioid pain medication}

When measured with an 11-point numerical rating scale (where $0=$ completely disagree and $10=$ completely agree), caregivers' greatest concerns related to opioids were side effects, addiction risk, and difficulty finding the cause of their child's pain (Table 3).

Caregiver fears, specifically those of their child becoming addicted to opioids (OR 1.12; 95\% CI 1.01 to 1.25 ) and side effects (OR 1.25; 95\% CI 1.11 to 1.42 ) harming their child, affected their willingness to accept opioids for persistent moderate pain (after appropriate doses of acetaminophen and ibuprofen) in the ED. Caregiver fears, specifically of their child becoming addicted to opioids (OR 1.19; 95\% CI 1.07 to 1.32) 


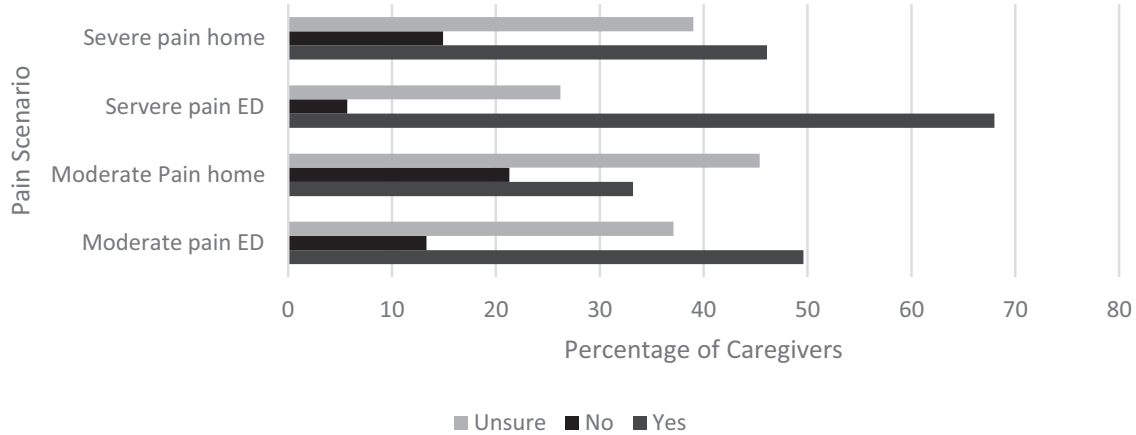

Figure 1. Caregiver willingness accept opioids in the ED and for home in moderate and severe pain scenarios ( $\mathrm{n}=512)$. ED Emergency department.

A

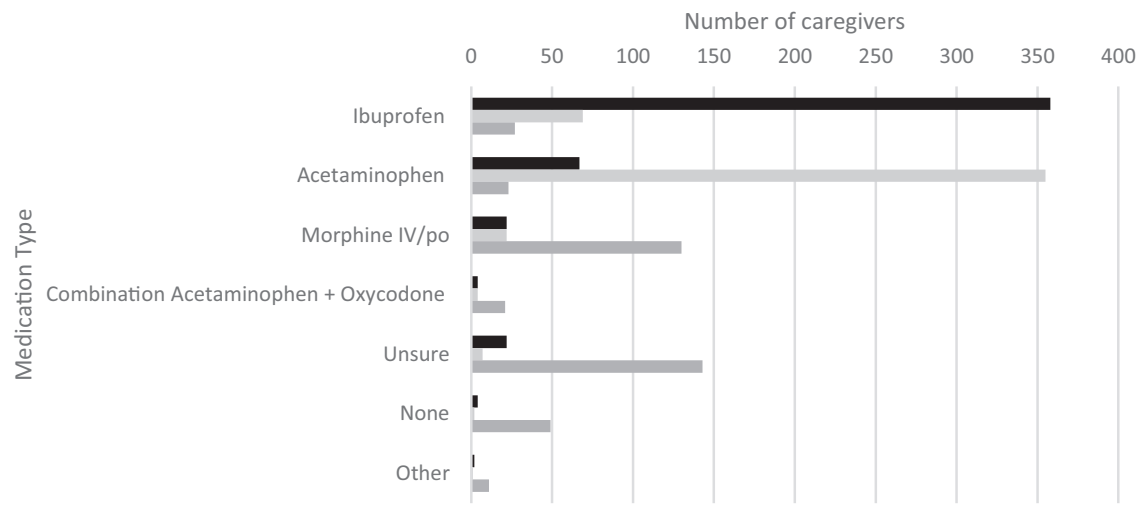

B

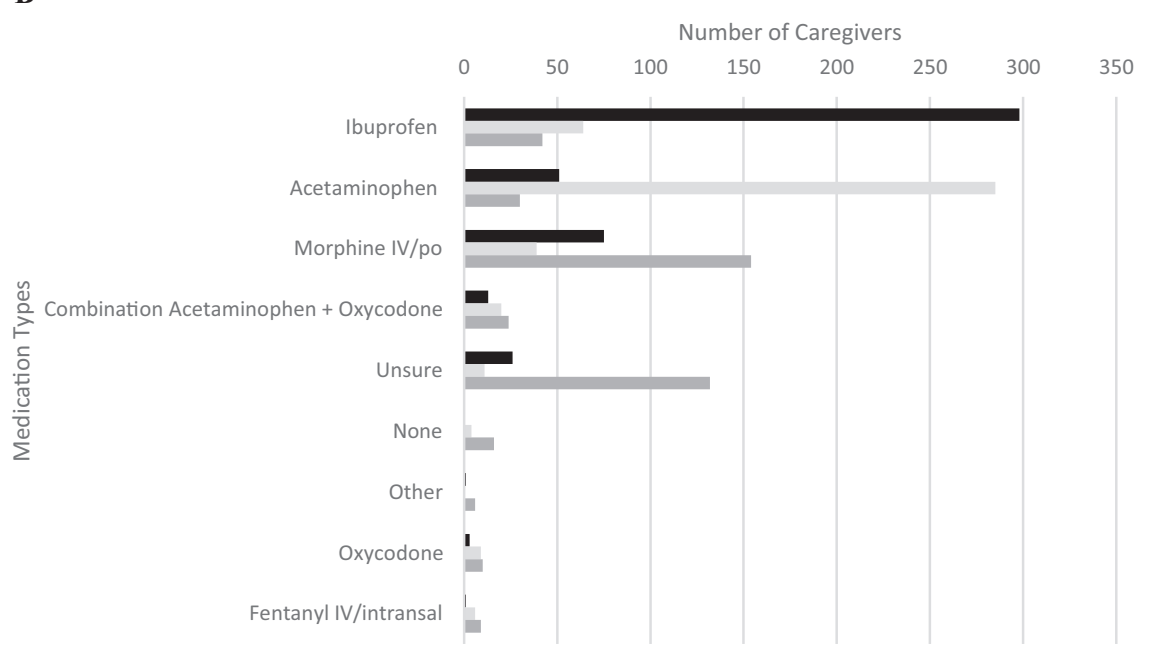

Figure 2. Caregiver perceptions of the most appropriate pain medication for their child in moderate and severe pain. (A) Ranking of most appropriate pain medications in moderate pain. (B) Ranking of most appropriate pain medications in severe pain $(\mathrm{n}=517)$.

and their child overdosing (OR 1.15; 95\% CI 1.04 to 1.27 ), affected willingness to accept opioids for persistent moderate pain for at-home use.
Caregivers identified the most reliable source of opioid information to be their doctor $(330 / 510,64.7 \%)$, medical articles $(62 / 510,12.2 \%)$, personal experience $(33 / 510,6.5 \%)$, second 
Table 2. Children's and caregivers' reported previous experience with pain medications $(\mathrm{n}=517)$

\begin{tabular}{|c|c|c|c|}
\hline Pain medication & $\begin{array}{l}\text { Child } \\
\text { experience } \\
\text { (at home) }\end{array}$ & $\begin{array}{l}\text { Child } \\
\text { experience } \\
\text { (health care } \\
\text { facility) }\end{array}$ & $\begin{array}{l}\text { Caregiver } \\
\text { personal } \\
\text { use }\end{array}$ \\
\hline & n (\%) & n (\%) & n (\%) \\
\hline Ibuprofen & $472(91.3)$ & $388(75)$ & $421(81.4)$ \\
\hline Acetaminophen & $457(88.4)$ & $357(69.1)$ & $392(75.8)$ \\
\hline $\begin{array}{l}\text { Morphine, by } \\
\text { mouth }\end{array}$ & $13(2.5)$ & $18(3.5)$ & $51(9.9)$ \\
\hline Morphine IV & $1(0.2)$ & $46(8.9)$ & $90(17.4)$ \\
\hline $\begin{array}{l}\text { Oxycodone- } \\
\text { containing } \\
\text { products }\end{array}$ & $3(0.6)$ & $6(1.2)$ & $128(24.8)$ \\
\hline $\begin{array}{l}\text { Codeine- } \\
\text { containing } \\
\text { products }\end{array}$ & $35(6.7)$ & $38(6.3)$ & $339(65.6)$ \\
\hline Oxycontin & 0 & 0 & $30(5.8)$ \\
\hline Hydromorphone & 0 & $2(0.4)$ & $22(4.3)$ \\
\hline $\begin{array}{l}\text { Hydrocodone }+ \\
\text { Acetaminophen }\end{array}$ & $1(0.2)$ & 0 & $5(1)$ \\
\hline $\begin{array}{l}\text { Tramadol- } \\
\text { containing } \\
\text { products }\end{array}$ & $2(0.4)$ & $3(0.6)$ & $104(20.1)$ \\
\hline Naproxen & $31(6)$ & $9(1.7)$ & $135(26.1)$ \\
\hline Other $^{\wedge}$ & $4(0.8)$ & $5(1.0)$ & $12(2.3)$ \\
\hline $\begin{array}{l}\text { Unsure what was } \\
\text { given }\end{array}$ & $4(0.8)$ & $65(12.6)$ & $30(5.8)$ \\
\hline None & $11(2.1)$ & $49(9.5)$ & $18(3.5)$ \\
\hline
\end{tabular}

${ }^{*}$ Oxycodone OR Oxycodone + acetaminophen (Percocet).

${ }^{* *}$ Codeine OR codeine +acetaminophen.

${ }^{\wedge}$ Child (at home): Biofreeze $(n=1)$, clonixine $(n=1)$, homeopathic remedies $(\mathrm{n}=1)$; Child (health care facility): fentanyl $(\mathrm{n}=1)$, laughing gas $(n=1)$, biofreeze $(n=1)$, Demerol $(n=1)$; Caregiver: demerol $(n=2)$, unspecified injection pain medication $(n=1)$, toradol $(n=3)$, cambia $(n=1)$, fentanyl $(n=1)$, maxalt $(n=1)$, propofol $(n=1)$.

\# Tramadol OR Acetaminophen + Tramadol (Tramacet).

hand experience $(20 / 510,3.9 \%)$, nurse $(17 / 510,3.3 \%)$, other health care professional $(11 / 510,2.2 \%)$, and social media $(9 / 510,1.8 \%)$. When asked what caregivers had heard about opioids in recent news, the three most common themes were 'overdose/fatality' ( $\mathrm{n}=65)$, 'fentanyl/carfentanill' $(\mathrm{n}=45)$, and 'abuse/ recreational use/parties' $(\mathrm{n}=38)$.

\section{DISCUSSION}

Although caregivers report highly prioritizing pain management (19), our study found that there is continued reluctance to accept opioids for their child, especially in the postdischarge setting. Furthermore, caregivers demonstrated a high degree of uncertainty in hypothetical situations, with more than one third of caregivers unsure whether they would accept opioids in the ED and nearly half of them unsure whether they would accept opioids upon discharge for moderate pain. Areas of caregiver concerns were side effects, overdose, addiction risk, and masking of diagnosis, with the first three having a modest impact on reported willingness to accept opioids for their children.

Whiston et al. found that caregivers had high acceptance of analgesia offered in the ED and they concluded that caregiver refusal of analgesia was not a major barrier to children's pain management (24). However, less than $10 \%$ of the children were offered opioids in their study, with the majority receiving ibuprofen and acetaminophen. Their study did not explore whether there was a difference in analgesic acceptance rates between opioids and nonopioid medications. Several studies have shown that caregivers often withhold analgesics from their child at home despite ongoing pain $(25,26)$. Similarly, caregivers in our study demonstrated high levels of willingness to accept analgesics in the ED, with lower willingness to accept opioids. These findings suggest that caregiver refusal of analgesia is not a barrier to pain management when they are offered nonopioids; however, there may be an important barrier when escalation of analgesia required opioid use. Previous research has shown that increasing caregiver knowledge of analgesics and their side effects improves pain management in children $(7,27,28)$. Given that 37 to $45 \%$ of caregivers reported uncertainty surrounding opioid analgesic decisions, there is an urgent need for clear caregiver education regarding risks and benefits of opioid use in children.

Opioid side effects were the highest rated concern from caregivers, along with overdose and addiction. Central nervous system effects, nausea, constipation, and respiratory depression are well-recognized adverse effects of opioids (29-31), with over $20 \%$ of children receiving opioids experiencing an adverse effect (17). In fact, caregivers' fear of adverse drug events was associated with a reduced rate of administering opioids to their child even when warranted (6). Such under-treatment of children's pain may be addressed if caregivers are provided with anticipatory guidance regarding appropriate use of pain medications and tools to manage possible opioid side effects (e.g., stool softeners).

Among caregivers' primary concerns, the addictive potential of opioids was rated highly. The current opioid crisis has brought increased regulation of opioid prescribing in 'high opioid prescribing settings' such as EDs, because it was thought that these areas might be contributing to the crisis $(2,3)$. It has been shown that opioid-naive adult patients who were prescribed opioids for acute pain in the ED were at increased risk 
Table 3. Caregiver opioid perceptions (reported with a $0-10$ scale, where $0=$ completely disagree, and $10=$ completely agree)

\begin{tabular}{|c|c|c|c|c|c|c|c|}
\hline \multirow[t]{2}{*}{ Statement } & \multicolumn{2}{|c|}{ Edmonton } & \multicolumn{2}{|c|}{ London } & \multicolumn{3}{|l|}{ ALL } \\
\hline & $\mathbf{N}$ & Median & $\mathbf{N}$ & Median & Median & $25 \%$ ile & $75 \%$ ile \\
\hline I worry about giving my child OPM & 213 & 7 & 296 & 8 & 8 & 5 & 10 \\
\hline My child may become addicted to OPM & 213 & 5 & 295 & 5 & 5 & 2 & 9 \\
\hline $\begin{array}{l}\text { Another person may become addicted to OPM } \\
\text { prescribed to my child }\end{array}$ & 213 & 1 & 295 & 0 & 0 & 0 & 5 \\
\hline $\begin{array}{l}\text { My child may use OPM for purpose other than } \\
\text { pain }\end{array}$ & 212 & 1 & 294 & 0 & 0 & 0 & 4 \\
\hline Side effects of OPM can harm my child & 213 & 5 & 296 & 7 & 6 & 4 & 10 \\
\hline My child might OD on OPM prescribed to them & 210 & 5 & 296 & 5 & 5 & 1 & 7 \\
\hline OPM will make it hard to find the cause of pain & 208 & 5 & 294 & 5 & 5 & 2 & 7 \\
\hline $\begin{array}{l}\text { Child will be treated poorly if I disagree with } \\
\text { doctor about OPM }\end{array}$ & 208 & 1 & 295 & 1 & 1 & 0 & 5 \\
\hline $\begin{array}{l}\text { OPM prescribed to my child may be diverted to } \\
\text { someone not in family, like friend }\end{array}$ & 209 & 0 & 295 & 0 & 0 & 0 & 2 \\
\hline
\end{tabular}

OD overdose; OPM opioid pain medications

for additional opioid use, but not necessarily misuse, at 1 year (32). A limited number of methodologically challenged studies have proposed that prescription opioid use in children before adulthood increases the risk of future opioid misuse $(33,34)$. However, there is a paucity of evidence to reliably demonstrate that future opioid addiction is caused by short term opioid use in children (35). Nevertheless, with $15 \%$ of caregivers stating that they or a family member had a substance use disorder, the need for judicious opioid prescribing, in all settings, is highlighted.

Historically, another barrier to adequate analgesia has been the fear of masking the cause of pain with treatment (36). Caregivers continue to echo this, despite literature that disproves this theory $(37,38)$. This finding suggests that there is an important gap in knowledge translation to families. Given that almost two-thirds of caregivers identify physicians as their primary source of opioid information, physicians play a leading role in family education regarding the lack of rationale in withholding adequate analgesia.

Caregivers in our study reported acetaminophen and ibuprofen as the most used and most appropriate analgesia for children; this is consistent with existing literature $(17,30,39,40)$. Surprisingly, codeine-containing products were the third most commonly reported pain medication used at home, despite multiple federal warnings regarding their use in children across North America (41).

While opioids have a role in some scenarios of acute pain, there are many effective alternatives that do not have the adverse effects and risks of opioids, including nonopioid medications, physical, and psychological interventions $(42,43)$. A 2019 survey of over 1,000 parents suggests that parents often don't ask about opioid alternatives; $59 \%$ of parents stated that they would ask their physician about pain management options, but only one third of those whose children were prescribed opioids actually did (44). This is further compounded by gross misinformation, with $15 \%$ of parents in this same survey incorrectly stating that antibiotics were an effective pain reliever. It is imperative that clinicians engage in clear conversations with families regarding first-line use of nonopioid medications in conjunction with physical and psychological interventions. When opioids are recommended, they should be used as combination therapy, rather than monotherapy (30).

\section{Limitations}

Caregivers in this study answered hypothetical questions, and we did not collect children's pain scores of final diagnoses, so caregiver responses may not fully reflect real-life decisions and cannot be correlated to actual presentation. However, given that 9 out of 10 children accompanying the included caregivers had suffered a limb injury, the hypothetical questions closely mirrored their presenting complaint. This study was only conducted at two sites and during hours of convenience for research staffing, so the results may not be widely generalizable. Finally, our study is limited to only MSK injury. We believed this to be an appropriate exemplar for studying opioid pain management in otherwise healthy children, but results may not be generalizable to all other conditions. 


\section{CONCLUSIONS}

Caregivers' comfort with opioids for analgesia is limited and only half of caregivers would accept opioids for moderate pain after acute injury (and approximately $70 \%$ for severe pain), even when nonopioid pain medications were inadequate. A further one third endorsed uncertainty about acceptance, primarily due to their lack of familiarity, fear of side effects, addiction risk, and perceived risk of masking the diagnosis. These findings highlight the need for tools such as information summaries to improve communication and patient education so we can better guide conversations with families regarding pain management and risk balance. Future qualitative interviews would help us understand caregiver motivations when making opioid-related decisions. Finally, urgent research is required to determine the relationship between short-term opioid use in children with moderate to severe acute pain and the future risk of developing an opioid use disorder.

\section{SUPPLEMENTARY DATA}

Supplementary data are available at Paediatrics \& Child Health Online.

\section{Acknowledgements}

We would like to acknowledge the research assistants and study coordinators at the two sites (especially Kamary Coriolano DaSilva) for their invaluable contribution, as well as the Stollery Children's Hospital Pediatric Emergency Medicine Research Group.

Funding: This research has been funded by the generous support of the Stollery Children's Hospital Foundation through the Women and Children's Health Research Institute.

Financial disclosure: The authors have no financial relationships relevant to this article to disclose.

Potential Conflicts of Interest: Dr. Dong reports personal fees from College of Physicians and Surgeons of Alberta and grants from the Canadian Research Initiative in Substance Misuse outside the submitted work. There are no other disclosures. All authors have submitted the ICMJE Form for Disclosure of Potential Conflicts of Interest. Conflicts that the editors consider relevant to the content of the manuscript have been disclosed.

\section{References}

1. Kankkunen P, Vehviläinen-Julkunen K, Pietilä AM, Kokki H, Halonen P. Parents' perceptions and use of analgesics at home after children's day surgery. Paediatr Anaesth 2003;13(2):132-40.

2. Dart RC, Severtson SG, Bucher-Bartelson B. Trends in opioid analgesic abuse and mortality in the United States. N Engl J Med 2015;372(16):1573-4.

3. Barnett ML, Olenski AR, Jena AB. Opioid-prescribing patterns of emergency physicians and risk of long-term use. N Engl J Med 2017;376(7):663-73.

4. Ali H, Kircher J, Meyers C, MacLellan J, Ali S. Canadian emergency medicine residents' perspectives on pediatric pain management. Cjem 2015;17(5):507-15.

5. Ali S, Poonai N. Parents' preferences on pain treatment, even when faced with medication dilemmas, influence their decisions to administer opioids in children. Evid Based Nurs 2016;19(2):51-2
6. Voepel-Lewis T, Zikmund-Fisher BJ, Smith EL, Zyzanski S, Tait AR. Parents' preferences strongly influence their decisions to withhold prescribed opioids when faced with analgesic trade-off dilemmas for children: A prospective observational study. Int J Nurs Stud 2015;52(8):1343-53.

7. Voepel-Lewis T, Zikmund-Fisher BJ, Smith EL, Redman RW, Zyzanski S, Tait AR. Parents' analgesic trade-off dilemmas: How analgesic knowledge Influences their decisions to give opioids. Clin J Pain 2016;32(3):187-95.

8. Twycross AM, Williams AM, Bolland RE, Sunderland R. Parental attitudes to children's pain and analgesic drugs in the United Kingdom. J Child Health Care 2015;19(3):402-11.

9. Forward SP, Brown TL, McGrath PJ. Mothers' attitudes and behavior toward medicating children's pain. Pain 1996;67(2-3):469-74.

10. Pagnamenta R, Benger JR. Factors influencing parent satisfaction in a children's emergency department: Prospective questionnaire-based study. Emerg Med J 2008;25(7):417-9.

11. Locke R, Stefano M, Koster A, Taylor B, Greenspan J. Optimizing patient/caregiver satisfaction through quality of communication in the pediatric emergency department. Pediatr Emerg Care 2011;27(11):1016-21.

12. Byczkowski TL, Fitzgerald M, Kennebeck S, et al. A comprehensive view of parental satisfaction with pediatric emergency department visits. Ann Emerg Med 2013;62(4):340-50.

13. Byczkowski TL, Gillespie GL, Kennebeck SS, Fitzgerald MR, Downing KA, Alessandrini EA. Family-centered pediatric emergency care: A framework for measuring what parents want and value. Acad Pediatr 2016;16(4):327-35.

14. Magaret ND, Clark TA, Warden CR, Magnusson AR, Hedges JR. Patient satisfaction in the emergency department-a survey of pediatric patients and their parents. Acad Emerg Med 2002;9(12):1379-88.

15. Chan L, Russell TJ, Robak N. Parental perception of the adequacy of pain control in their child after discharge from the emergency department. Pediatr Emerg Care 1998;14(4):251-3.

16. Clark E, Plint AC, Correll R, Gaboury I, Passi B. A randomized, controlled trial of acetaminophen, ibuprofen, and codeine for acute pain relief in children with musculoskeletal trauma. Pediatrics 2007;119(3):460-7.

17. Le May S, Ali S, Khadra C, et al. Pain management of pediatric musculoskeletal injury in the emergency department: A systematic review. Pain Res Manag 2016;2016:4809394.

18. Poonai N, Bhullar G, Lin K, et al. Oral administration of morphine versus ibuprofen to manage postfracture pain in children: A randomized trial. CMAJ 2014;186(18):1358-63.

19. Bialy L, Plint AC, Freedman SB, Johnson DW, Curran JA, Stang AS; Pediatric Emergency Research Canada (PERC). Pediatric Emergency Research Canada (PERC): Patient/family-informed research priorities for pediatric emergency medicine. Acad Emerg Med 2018;25(12):1365-74.

20. Burns KE, Duffett M, Kho ME, et al.; ACCADEMY Group. A guide for the design and conduct of self-administered surveys of clinicians. CMAJ 2008;179(3):245-52.

21. Harris PA, Taylor R, Thielke R, Payne J, Gonzalez N, Conde JG. Research electronic data capture (REDCap)-a metadata-driven methodology and workflow process for providing translational research informatics support. J Biomed Inform 2009;42(2):377-81.

22. Turk DC, Swanson KS, Gatchel RJ. Predicting opioid misuse by chronic pain patients: A systematic review and literature synthesis. Clin J Pain 2008;24(6):497-508.

23. Webster LR. Risk factors for opioid-use disorder and overdose. Anesth Analg 2017;125(5):1741-8

24. Whiston $\mathrm{C}$, Ali S, Wright B, et al. Is caregiver refusal of analgesics a barrier to pediatric emergency pain management? A cross-sectional study in two Canadian centres. CJEM 2018;20(6):892-902.

25. Rony RY, Fortier MA, Chorney JM, Perret D, Kain ZN. Parental postoperative pain management: Attitudes, assessment, and management. Pediatrics 2010;125(6):e1372-8.

26. Abou-Karam M, Dubé S, Kvann HS, et al. Parental report of morphine use at home after pediatric surgery. J Pediatr 2015;167(3):599-604.e1-2.

27. Dudley N, Ackerman A, Brown KM, Snow SK; American Academy of Pediatrics Committee on Pediatric Emergency Medicine; American College of Emergency Physicians Pediatric Emergency Medicine Committee; Emergency Nurses Association Pediatric Committee. Patient- and family-centered care of children in the emergency department. Pediatrics 2015;135(1):e255-72.

28. American Academy of Pediatrics. Committee on Psychosocial Aspects of C, Family H, Task Force on Pain in Infants C, Adolescents. The assessment and management of acute pain in infants, children, and adolescents. Pediatrics 2001;108:793-7. 
29. Drendel AL, Gorelick MH, Weisman SJ, Lyon R, Brousseau DC, Kim MK. A randomized clinical trial of ibuprofen versus acetaminophen with codeine for acute pediatric arm fracture pain. Ann Emerg Med 2009;54(4):553-60.

30. Hartling L, Ali S, Dryden DM, et al. How safe are common analgesics for the treatment of acute pain for children? A systematic review. Pain Res Manag 2016;2016:5346819.

31. Wester K, Jönsson AK, Spigset O, Druid H, Hägg S. Incidence of fatal adverse drug reactions: A population based study. Br J Clin Pharmacol 2008;65(4):573-9.

32. Hoppe JA, Kim H, Heard K. Association of emergency department opioid initiation with recurrent opioid use. Ann Emerg Med 2015;65(5):493-499.e4.

33. Miech R, Johnston L, O’Malley PM, Keyes KM, Heard K. Prescription opioids in adolescence and future opioid misuse. Pediatrics 2015;136(5):e1169-77.

34. McCabe SE, Cranford JA, West BT. Trends in prescription drug abuse and dependence, co-occurrence with other substance use disorders, and treatment utilization Results from two national surveys. Addict Behav 2008;33(10):1297-305.

35. Axeen S, Seabury SA, Menchine M. Emergency department contribution to the prescription opioid epidemic. Ann Emerg Med 2018;71(6):659-667.e3.

36. Kim MK, Galustyan S, Sato TT, Bergholte J, Hennes HM. Analgesia for children with acute abdominal pain: A survey of pediatric emergency physicians and pediatric surgeons. Pediatrics 2003;112(5):1122-6.

37. Manterola C, Vial M, Moraga J, Astudillo P. Analgesia in patients with acute abdominal pain. Cochrane Database Syst Rev 2011;19(1):CD005660.

38. Bromberg R, Goldman RD. Does analgesia mask diagnosis of appendicitis among children? Can Fam Physician 2007;53(1):39-41.

39. Kircher J, Drendel AL, Newton AS, et al. Acute pediatric musculoskeletal pain management in North America: A practice variation survey. Clin Pediatr (Phila) 2014;53(14):1326-35.

40. Kircher J, Drendel AL, Newton AS, Dulai S, Vandermeer B, Ali S. Pediatric musculoskeletal pain in the emergency department: A medical record review of practice variation. CJEM 2014;16(6):449-57.
41. Health Canada. New Safety Measures for Prescription Codeine and Hydrocodone to Further Restrict Use in Children and Adolescents. <http://healthycanadians. gc.ca/recall-alert-rappel-avis/hc-sc/2016/59584a-eng.php> (Accessed April 3, 2019).

42. Anie KA, Green J. Psychological therapies for sickle cell disease and pain. Cochrane Database Syst Rev 2015;8(5):CD001916.

43. Birnie KA, Noel M, Chambers CT, Uman LS, Parker JA. Psychological interventions for needle-related procedural pain and distress in children and adolescents. Cochrane Database Syst Rev 2018;10:CD005179.

44. American Society of Anesthesiologists. Parents Worried About Risks, but Still Think Opioids are Best for Kids' Pain Relief, Nationwide Survey Shows. American Society of Anesthesiologists, 2019. <https://www.asahq.org/about-asa/newsroom/news-releases/2019/01/physaneswk19-news-release> (Accessed March $25,2019)$.

\section{Appendix 1. Pediatric Emergency Research Canada nonauthor contributors}

The following Pediatric Emergency Research Canada members are nonauthor contributors:

Dr. Stephen B. Freedman (University of Calgary, Calgary, Alberta, Canada)

Dr. Esli Osmanlliu (McGill University, Montreal, Quebec, Canada)

Marie-Christine Auclair (Universite de Montreal, Montreal, Quebec, Canada)

Dr. Amy Plint (University of Ottawa, Ottawa, Ontario, Canada)

Dr. Quynh Doan (University of British Columbia, Vancouver, British Columbia, Canada)

Dr. Vikram Sabhaney (University of British Columbia, Vancouver, British Columbia, Canada)

Dr. Roger Zemek (University of Ottawa, Ottawa, Ontario, Canada)

Rebecca Emerton (University of Calgary, Calgary, Alberta, Canada) 